Research Article

\title{
Detailed Study on the Mechanical Properties and Activation Energy of Natural Rubber/Chloroprene Rubber Blends during Aging Processes
}

\author{
Quang Nguyen Trong, ${ }^{1,2}$ Hung Dang Viet, ${ }^{1}$ Linh Nguyen Pham Duy ${ }^{\mathbb{D}},{ }^{1}$ Chuong Bui, \\ and Duong Duc La ${ }^{3,4}$ \\ ${ }^{1}$ Center for Polymer Composite and Paper, Hanoi University of Science \& Technology, Hanoi, Vietnam \\ ${ }^{2}$ Hung Yen University, Hung Yen, Vietnam \\ ${ }^{3}$ Laboratory of Advanced Materials Chemistry, Advanced Institute of Materials Science, Ton Duc Thang University, \\ Ho Chi Minh, Vietnam \\ ${ }^{4}$ Faculty of Applied Sciences, Ton Duc Thang University, Ho Chi Minh, Vietnam
}

Correspondence should be addressed to Linh Nguyen Pham Duy; linhnpd@gmail.com and Duong Duc La; laducduong@tdtu.edu.vn

Received 7 June 2020; Revised 23 September 2020; Accepted 25 October 2020; Published 17 November 2020

Academic Editor: Gulaim A. Seisenbaeva

Copyright ( 2020 Quang Nguyen Trong et al. This is an open access article distributed under the Creative Commons Attribution License, which permits unrestricted use, distribution, and reproduction in any medium, provided the original work is properly cited.

\begin{abstract}
Selection of a suitable thermal aging process could render desirable mechanical properties of the rubbers or blended rubbers. In this work, the effect of the aging processes on the mechanical properties and activation energies of natural rubbers (NR) and NR/ chloroprene rubbers (CR) blends with low CR contents (5-10\%) was investigated. Three aging processes including heat aging (at $110^{\circ} \mathrm{C}$ for 22 hours), mechanical aging (under dynamic loading to $140 \%$ strain for 16000 cycles), and complex aging (heat and mechanical aging) were studied. The results revealed that the compatibility of CR in natural rubber matrix had a significant effect on the dynamic properties of the blended rubber and negligible effect on the static properties. The changes in activation energies of the blended rubber during aging processes were calculated using Arrhenius relation. The calculated changes $\left(\Delta U_{\mathrm{c}}, \Delta U_{\mathrm{d}}\right.$, and $\left.\Delta U_{\mathrm{T}}\right)$ in activation energies were consistent with the results of mechanical properties of the blended rubber. Interestingly, the change in activation energies using complex aging conditions $\left(\Delta U_{c}\right)$ was mostly equal to the total changes in activation energies calculated separately from heat aging $\left(\Delta U_{\mathrm{T}}\right)$ and mechanical aging $\left(\Delta U_{\mathrm{d}}\right)$ conditions. This indicates that, in complex aging conditions, the heat and dynamic loading factors act independently on the properties of the blended rubber.
\end{abstract}

\section{Introduction}

Natural rubber (NR), a very important elastomer, has been widely used in wide range of technical and civil applications. However, the disadvantage of low aging resistance limits the application of natural rubber in many practical applications. In order to enhance the aging resistance of $\mathrm{NR}$, one of the effective methods is to blend NR with the synthetic rubbers, which have good aging resistance such as ethylene propylene diene monomer (EPDM) and chloroprene rubber (CR) $[1,2]$. Among these synthetic rubbers, $\mathrm{CR}$ is often used to improve the weather and ozone resistance properties for natural rubber. However, the CR has low compatibility in the NR matrix, which results in lower mechanical properties of blended rubbers in comparison with pristine rubbers. Many works have been carried out on the compatibility and properties of NR/CR blends, such as network structure and stress relaxation [3] and mechanical properties $[4,5]$ on vulcanization characteristics [5, 6]. Zlata Harnjak-Murgie's group evaluated the change in network density of NR mixtures with various accelerators during heat aging [7]. The relationship between heat aging and rubber/rubber blends 
network was investigated by various methods $[3,8-10]$. Such relationship may also be used for the prediction of rubber behavior while aging conditions were changed [11].

It is well known that structure changes commonly lead to the changes in rubber properties during the aging processes. For example, utilization of heat aging process and various accelerator systems resulted in the change of dynamic properties of rubber $[12,13]$. Other mechanical properties such as tensile properties [14], hardness [15], and dielectric properties $[16,17]$ are also changed upon employment of different aging processes and accelerating systems. The aging process and mechanical loading are decisive factors on the service life of the rubber. The simultaneous effect of two factors (aging processes and mechanical loading) on the rubber service life has been studied in many works [18-22]. The service life of the rubber depended on several mechanical properties such as fatigue resistance, crack development, and tear strength [23-25]. Nevertheless, due to the complexity of the failure mechanism of rubbers in the aging process, rubber service life prediction is often based on a phenomenal approach, where the molecular mechanism of failure is not concerned. According to the phenomenal approach, two modes using Arrhenius relation or WilliamsLandel-Ferry (WLF) equation are commonly employed $[26,27]$. Arrhenius relation is often used in the case of aging with constant temperature. Several prediction methods have been developed relying on Arrhenius model [22, 27-31]. However, change in activation energy of the blended rubbers during the aging processes, which lead to change in mechanical properties, has not yet fully studied.

Herein, the relation of two aging process (heat and dynamic aging processes) is investigated through change in activation energy of the NR and NR/CR blends. Based on the determination of aging coefficients and Arrhenius-type equation for tensile strength, change in activation energy will be quantitatively evaluated, while rubbers are affected by the aforementioned factors simultaneously and separately.

\section{Experimental Section}

2.1. Materials. Natural rubber was obtained from a Vietnamese RSS company. Chloroprene rubber was purchased from Japan (M120). Carbon black, antidegradants RD and 4020, stearic acid, plasticizer 112, accelerators TMTD and TBBS, and $\mathrm{ZnO}$ were purchased from Xilong (China). All chemicals were used as received without any further purification.

Rubber blends were prepared following formulations listed in Table 1. A reference sample of natural rubber without addition of chloroprene rubber was prepared for comparison purpose.

2.2. Sample Preparation. Rubber and ingredients were mixed in internal mixer Baopin 8412 with rotor speed of $30 \mathrm{rpm}$ at temperature of $80^{\circ} \mathrm{C}$ for 13 minutes. Mixtures were stabilized at $25^{\circ} \mathrm{C}$ for 24 hours and vulcanized at $145^{\circ} \mathrm{C}$ for 10 minutes.

2.3. Mechanical Properties. The hardness (shore A) was determined by using TFCLOCKGS 790N (Japan). Tensile
TABLE 1: Rubber blends formulations.

\begin{tabular}{lccc}
\hline Ingredients & $\mathrm{NR}$ & $\mathrm{NR} / \mathrm{CR} 5$ & $\mathrm{NR} / \mathrm{CR} 10$ \\
\hline Natural rubber RSS & 100.0 & 95.0 & 90.0 \\
Chloroprene rubber M120 & 0 & 5.0 & 10.0 \\
Antidegradant RD & 1.5 & 1.5 & 1.5 \\
Antidegradant 4020 & 2.0 & 2.0 & 2.0 \\
Carbon black N330 & 33.0 & 33.0 & 33.0 \\
ZnO & 6.0 & 6.0 & 6.0 \\
Stearic acid & 2.0 & 2.0 & 2.0 \\
112 oil & 1.5 & 1.5 & 1.5 \\
Accelerator TBBS & 1.6 & 1.6 & 1.6 \\
Accelerator TMTD & 0.2 & 0.2 & 0.2 \\
Sulphur & 2.0 & 2.0 & 2.0 \\
\hline
\end{tabular}

strength and elongation at break were defined according to ISO 37:2005 standard using INSTRON 5582 equipment (USA). Permanent compression was determined according to ASTM D395-03:2008, and rebound property was estimated followed ASTM D2632-01 standard.

\subsection{Swelling Behavior and Network Density Calculation.} The swelling test was carried out in toluene solvent according to ISO $1817: 2005$.

Swelling degree is defined as follows:

$$
\Delta m=\frac{m_{1}-m_{0}}{m_{0}} .100 \%
$$

where $m_{0}$ and $m_{1}$ are the mass of sample before and after immersion into toluene. $\Delta m$ is the swelling degree, $\%$

Network density is calculated according to Flory-Rehner equation [32]:

$$
-\left[\ln \left(1-V_{2}\right)+V_{2}+\chi \cdot V_{2}^{2}\right]=V_{1} \cdot n \cdot\left(V_{2}^{1 / 3}-\frac{V_{2}}{2}\right),
$$

where $V_{1}$ is the mole partial volume of solvent, $V_{2}$ is the volume fraction of the sample at the saturated swell, and $\chi$ is the interaction parameter of rubber and solvent.

In the case of rubber blend, $X$ may be calculated according to the ratio of rubbers and interaction parameters between rubber and solvent as follows [11]:

$$
\chi_{\text {blend }}=\chi_{1} \cdot a+\chi_{2} \cdot b \text {, }
$$

where $\chi_{1}$ and $\chi_{2}$ are the interaction parameters of rubbers 1 and 2 with solvent and $\mathrm{a}$ and $\mathrm{b}$ are the weight part of rubbers 1 and 2.

For NR and toluene, $\chi=0.39$; for CR and toluene, $\chi=0.14[33]$.

2.5. Aging Coefficient. Aging coefficient was determined according to ISO $188: 1998$ as follows:

$$
k=\frac{\sigma}{\sigma_{o}}
$$

where $k$ is the aging coefficient and $\sigma_{o}, \sigma$ are the tensile strength before and after aging. 
2.6. Aging Conditions. The samples were aged following three aging regimes:

(1) Heat aging: samples were heated in an air oven at $110^{\circ} \mathrm{C}\left(383^{\circ} \mathrm{K}\right)$ for 22 hours. Then, samples were left at room temperature at least 24 hours before testing following ASTM D3190.

(2) Mechanical aging: samples were stressed under dynamic loading to $140 \%$ strain for 16000 cycles at room temperature and left for rest at least $24 \mathrm{~h}$ before testing.

(3) Complex aging: samples were firstly heated in an air oven at $110^{\circ} \mathrm{C}$ for $22 \mathrm{~h}$, followed by cooling at room temperature for $24 \mathrm{~h}$, and then stressed under dynamic loading to $140 \%$ strain for 16000 cycles. After that, the samples were left for rest at least $24 \mathrm{~h}$ before testing.

\section{Results and Discussion}

\subsection{Effect of CR on NR/CR Blend Properties}

3.1.1. Swelling Behavior of NR/CR Blends. Swelling behaviours in the toluene of NR and NR/CR blends are exhibited in Figure 1. From the value of saturated swelling determined from the curves in Figure 1, the "apparent" network densities of blends were calculated and the results are shown in Table 2 . It can be clearly seen from Figure 1 and Table 2 that although the swelling of $\mathrm{CR}$ in toluene is smaller than that of $\mathrm{NR}$, the addition of a small part of CR (5-10 phr) into NR leads to a higher swelling value of blends in comparison with the neat NR. It is of note that when the CR contents increase, the swelling value of NR/CR blends decreases. This is ascribed to the swelling of each rubber in solvent and the interaction of rubber on interphase surface. The NR/CR blends with low compatibility of rubbers and poor interaction on the interphase surface lead to solvent penetration into the interphase area easier than into rubbers, and as a result, the swelling property increases. Furthermore, low swelling behavior of CR might reduce the swelling of NR/CR blends. Therefore, at a low percentage of $\mathrm{CR}$ in the blend, the swelling decreases because the decreased swelling of CR is not enough to compensate the increased swelling from rubbers incompatibility. For the same reason, the swelling of NR/CR10 is lower than that of NR/CR5 but still higher in comparison with neat NR. That is why the "apparent" network density with neat NR is higher than of NR/CR blends.

3.1.2. Mechanical Properties. Illustrated in Figure 2 and Table 3 are the mechanical properties of the NR and NR/CR blends. It can be obvious that addition of CR results in the decrease of tensile strength and elongation at break of the NR/CR blends. Upon addition of 5 phr CR into the blend, the tensile strength and elongation at break decreased from $25 \mathrm{MPa}$ to $620 \%$ to $23.3 \mathrm{MPa}$ and $600 \%$, respectively. The further increase of CR contents to $10 \mathrm{phr}$ witnesses the slight increase in tensile strength (24.6) and elongation at break (605) in comparison with the NR/CR blends with $5 \mathrm{phr}$ CR, which is still significantly lower than that of neat NR. This might be due to the incompatibility of the CR in NR matrix at low content of CR. For other mechanical properties such as hardness and permanent compression, the addition of CR slightly increases these properties of the blends as shown in Table 3. These small changes in the mechanical properties indicate that the small amount of CR does not have a significant effect on the static mechanical properties of NR/CR blends.

3.1.3. Aging Coefficients. Aging coefficients of NR and NR/ CR blends were determined following equation (4) for three aging conditions and the results are presented in Table 4. It can be seen from Table 4 that, in heat aging condition, the small amounts of CR (5-10 phr) have almost no effect on aging resistance of NR/CR blend in comparison with neat NR. This might be ascribed to the high aging resistance of CR and the incompatibility of NR and CR. This result is in well agreement with the aforementioned mechanical properties. Interestingly, under dynamic loading of the mechanical aging condition, the aging coefficients of NR/CR blends are remarkably lower than that of the neat NR. This is because, under dynamic loading, the incompatibility of rubbers might clearly appear even at a low percentage of NR (5-10 phr). It can be clearly seen in the complex aging regime that the aging coefficients of NR/CR blends are lower than that of the neat NR. Thus, based on the aging coefficients, it can be concluded that the addition of the CR might change activation energy of NR/CR blend under various aging conditions.

\subsection{Change of Activation Energy in Aging Processes}

3.2.1. Theoretical Background. The activation energy may be considered as an energy barrier that must be overcome before materials break down. The relation between tensile strength and temperature may be described through Arrhenius-type equation [34]:

$$
\sigma=\text { A. } \exp \left(\frac{U_{o}}{R T}\right),
$$

where $\sigma$ is the tensile strength (MPa), A is the constant, $U_{\mathrm{o}}$ is the activation energy $\left(\mathrm{J} \cdot \mathrm{mol}^{-1}\right), R$ is the gas constant $\left(R=8.314 \mathrm{~J} \mathrm{~mol}^{-1} \mathrm{~K}^{-1}\right)$, and $T$ is the temperature $(\mathrm{K})$.

Before aging, $\sigma$ and $T$ are denoted as $\sigma_{\mathrm{o}}$ and $T_{\mathrm{o}}$, respectively. After aging, the tensile strength of the material is calculated as follows: 


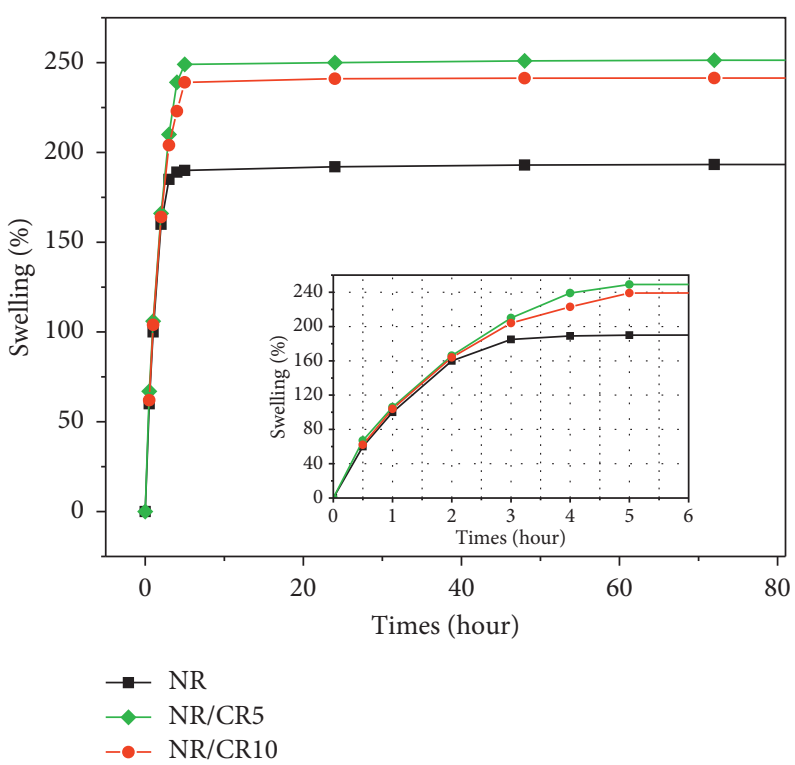

Figure 1: Swelling behaviour of NR and NR/CR blends.

TABLE 2: "Apparent" network density of NR and NR/CR blends.

\begin{tabular}{lccc}
\hline Materials & Interaction parameter $(\chi)$ & Saturated swelling $(\%)$ & Network density $\left(\mathrm{mol} / \mathrm{cm}^{3}\right)$ \\
\hline NR & 0.390 & 193.3 & $1.98 \times 10^{-4}$ \\
NR/CR5 & 0.377 & 251.4 & $1.56 \times 10^{-4}$ \\
NR/CR10 & 0.365 & 241.4 & $1.68 \times 10^{-4}$ \\
\hline
\end{tabular}

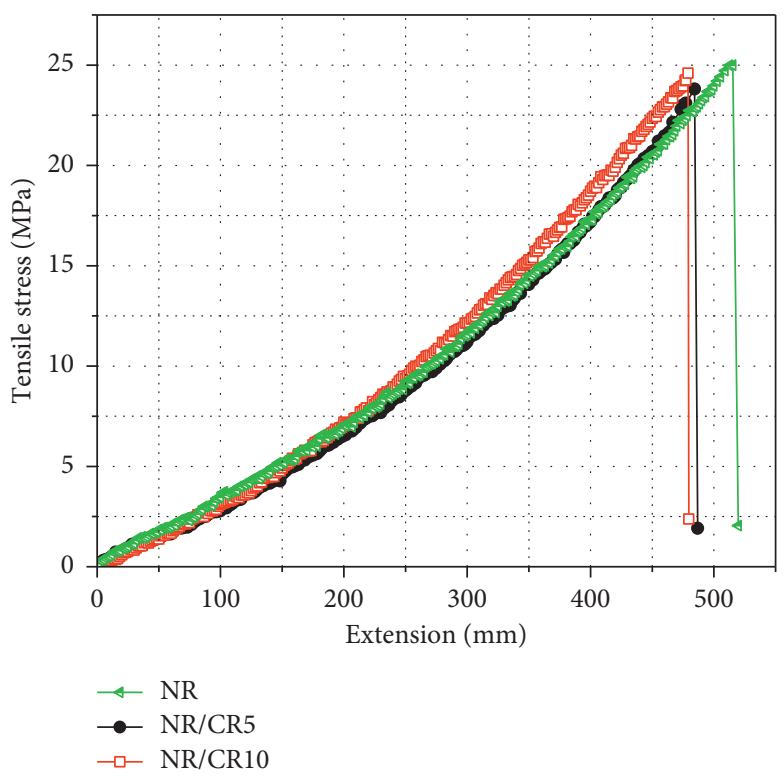

FIgURE 2: Stress-strain curves of NR and NR/CR blends.

TABLE 3: Mechanical properties of NR and NR/CR blends.

Materials Tensile strength (MPa) Elongation at break (\%) Residual elongation (\%) Hardness (shore A) Permanent compression (\%)

605

17

$\begin{array}{ll}54 & 12 \\ 55 & 15 \\ 55 & 13\end{array}$


TABLE 4: Tensile strengths and aging coefficients of NR and NR/CR blends determined at different aging conditions.

\begin{tabular}{|c|c|c|c|c|c|c|c|}
\hline \multirow[b]{2}{*}{ Materials } & \multirow{2}{*}{$\begin{array}{c}\text { Initial tensile } \\
\text { strength } \sigma_{o}(\mathrm{MPa})\end{array}$} & \multicolumn{2}{|c|}{ After heat aging } & \multicolumn{2}{|c|}{ After mechanical aging } & \multicolumn{2}{|c|}{ After complex aging } \\
\hline & & $\begin{array}{l}\text { Tensile strength } \sigma_{T} \\
(\mathrm{MPa})\end{array}$ & $k_{T}=\sigma_{T} / \sigma_{o}$ & $\begin{array}{l}\text { Tensile strength } \sigma_{d} \\
\qquad(\mathrm{MPa})\end{array}$ & $k_{d}=\sigma_{d} / \sigma_{o}$ & $\begin{array}{l}\text { Tensile strength } \sigma_{c} \\
(\mathrm{MPa})\end{array}$ & $k_{c}=\sigma_{c} / \sigma_{o}$ \\
\hline NR & 25.0 & 15.0 & 0.6 & 24.6 & 0.98 & 15.0 & 0.6 \\
\hline NR/CR5 & 23.3 & 14.0 & 0.6 & 17.5 & 0.75 & 11.3 & 0.49 \\
\hline $\begin{array}{l}\text { NR/ } \\
\text { CR10 }\end{array}$ & 24.6 & 14.0 & 0.57 & 18.6 & 0.76 & 10.2 & 10.42 \\
\hline
\end{tabular}

$$
\sigma_{\mathrm{ag}}=A \cdot \exp \left(\frac{U_{o}-\Delta U_{\mathrm{ag}}}{R T_{\mathrm{ag}}}\right)
$$

where [34] $\Delta U_{\mathrm{ag}}$ is decreased value of activation energy and $T_{\mathrm{ag}}$ is the aging temperature.

Dividing (6) by (5) and noting that $k=\sigma_{\mathrm{ag}} / \sigma_{o}$, one can obtain

$$
k=\frac{\sigma_{\mathrm{ag}}}{\sigma_{o}}=\exp \frac{\left(U_{o}-\Delta U_{a}\right)}{R T_{\mathrm{ag}}}-\frac{U_{o}}{R T_{o}} .
$$

After some conversions, we have

$$
\Delta U_{\mathrm{ag}}=\frac{\Delta T \cdot U_{o}}{T_{o}}-R \cdot T_{\mathrm{ag}} \ln k,
$$

where $\Delta T=T_{\mathrm{ag}}-T_{o}$

Formula (8) allows quantitatively determining the decrease in activation energy $\Delta U_{\text {ag }}$ during the aging process.

3.2.2. Decrease of Activation Energy during Heat Aging $\left(\Delta U_{T}\right)$. The calculated activation energies of the neat NR, $\mathrm{NR} / \mathrm{CR} 5$, and NR/CR10 are determined at the temperature of $25^{\circ} \mathrm{C}$ to be 24500,26134 , and $25231 \mathrm{~J} \mathrm{~mol}^{-1}$, respectively. In the experimental conditions with the aging temperature of $383 \mathrm{~K}$, where $\Delta T=383-298=85$, formula ( 8 ) may be converted to

$$
\Delta U_{T}=\frac{85}{298} U_{o}-383 \cdot R \cdot \ln k_{T} .
$$

Adding the $k_{T}$ values of all samples from Table 4 to (5), the decrease of activation energy during heat aging $\Delta U_{T}$ can be calculated as shown in Table 5. It can be seen from the table that the presence of CR has almost no effect on $\Delta U_{T}$ after heat aging, and the difference between $\Delta U_{T}$ of NR and $\mathrm{NR} / \mathrm{CR}$ blends is only in the range of $4-5 \%$.

3.2.3. Decrease of Activation Energy during Mechanical Aging $\left(\Delta U_{d}\right)$. During mechanical aging, the rubber samples suffered from dynamic loading at room temperature (298 K), and as a result, $\Delta T=0$ and (8) is converted to

$$
\Delta U_{d}=-298 \cdot R \cdot \ln k_{d} .
$$

Adding the $k_{d}$ values for all samples from Table 4 to (10), $\Delta U_{d}$ can be calculated as shown in Table 6. It is obvious that, in mechanical aging, the CR content is of significant effect on activation energy of the rubber blends. The changes in activation energies $\Delta U_{d}$ of NR/CR blends are much higher (1819 times) than that of the neat NR although the CR contents are small; hence, dynamic loading may strongly reduce $\Delta U_{d}$ of NR/CR blends, while it has almost no effect on $\Delta U_{d}$ of the neat NR. These results are consistent with the swelling behavior discussed previously.

\subsubsection{Decrease of Activation Energy during Complex Aging} $\Delta U_{c}$. In the complex aging condition, the tensile strength of samples decreases by both factors of heat and dynamic loading. Formula (8) can be converted to

$$
\Delta U_{c}=\frac{85}{298} U_{o}-383 \cdot R \cdot \ln k_{c} .
$$

Using (11) with the $k_{\mathrm{c}}$ values from Table $4, \Delta U_{c}$ for all samples were calculated and presented in Table 7. In complex aging condition, the activation energies of NR/CR blends also decrease significantly in comparison with the activation energy of the neat NR, but lower than that obtained from mechanical aging. Even these differences in activation energy between NR and NR/CR blends are rather small (only around 10-15\%), it is also demonstrated that CR has reasonable effect on the activation energy of the NR/CR blends during the complex aging. It can be also concluded that the $\Delta U_{c}$ (complex aging) values depend on both $\Delta U_{t}$ (from heat aging) and $\Delta U_{d}$ (from mechanical aging). The $\Delta \mathrm{U}_{c}$ calculated from (11) is the sum of $\Delta U_{t}+\Delta U_{d}$ determined from (9) and (10), and as a result, the relation of aging processes can be evaluated and the results are shown in Table 8.

It is obvious from Table 8 that low contents ( $5-10 \mathrm{phr}$ ) of CR significantly decrease activation energy of NR/CR blends during the mechanical aging process, which means that the incompatibility behavior of NR and CR rubbers is mainly expressed in dynamic conditions. The decrease of tensile strength in complex aging conditions may be from heat aging, where $\Delta U_{T}$ is higher than $\Delta U_{d}$ about 13-14 times. When the rubber samples are under both heat and dynamic loading, these factors may act independently. 
TABLE 5: $\Delta U_{T}$ of NR and NR/CR blends after the heat aging.

\begin{tabular}{lcc}
\hline Materials & $k_{T}$ & $\Delta U_{T,}\left(\mathrm{~J} . \mathrm{mol}^{-1}\right)$ \\
\hline NR & 0.6 & 8605 \\
NR/CR5 & 0.6 & 9066 \\
NR/CR10 & 0.57 & 8983 \\
\hline
\end{tabular}

TABLE 6: $\Delta U_{d}$ of NR and NR/CR blends after mechanical aging.

\begin{tabular}{lcc}
\hline Materials & $k_{T}$ & $\Delta U_{d}\left(\mathrm{~J} \cdot \mathrm{mol}^{-1}\right)$ \\
\hline NR & 0.98 & 37 \\
NR/CR5 & 0.75 & 707 \\
NR/CR10 & 0.76 & 690 \\
\hline
\end{tabular}

TABLE 7: $\Delta \mathrm{U}_{\mathrm{c}}$ of NR and NR/CR blends after the complex aging.

\begin{tabular}{lcc}
\hline Materials & $k_{T}$ & $\Delta U_{c}\left(\mathrm{~J} \cdot \mathrm{mol}^{-1}\right)$ \\
\hline NR & 0.6 & 8605 \\
NR/CR5 & 0.493 & 9697 \\
NR/CR10 & 0.415 & 9988 \\
\hline
\end{tabular}

TABLE 8: Comparison of $\Delta U_{T}, \Delta U_{d}$, and $\Delta U_{c}$ of NR and NR/CR blends.

\begin{tabular}{lccccc}
\hline Materials & $\Delta U_{c}\left(\mathrm{~J} \cdot \mathrm{mol}^{-1}\right)$ & $\Delta U_{T}\left(\mathrm{~J}_{\mathrm{mol}} \mathrm{mo}^{-1}\right)$ & $\Delta U_{d}\left(\mathrm{~J} \cdot \mathrm{mol}^{-1}\right)$ & $\Delta U_{t}+\Delta U_{d}\left(\mathrm{~J} \cdot \mathrm{mol}^{-1}\right)$ & $\Delta U_{c} /\left(\Delta U_{T}+\Delta U_{d}\right)^{1(\%)}$ \\
\hline NR & 8605 & 8605 & 37 & 8642 & 99.6 \\
NR/CR5 & 9697 & 9066 & 707 & 9773 & 99.2 \\
NR/CR10 & 9988 & 9983 & 690 & 9673 & 103.2 \\
\hline
\end{tabular}

\section{Conclusions}

In summary, the detailed investigation on the mechanical properties and the change in activation energies of the natural rubber/chloroprene rubber blends have been successfully presented. Effect of the CR content on the mechanical properties and especially activation energies of the NR/CR blends under various aging conditions of heat, mechanical, and complex aging has been studied. The incompatibility between NR and CR in NR/CR blends at low CR contents of 5-10 phr has negligible effects on static mechanical properties of the rubber blends. However, rubber incompatibility causes significant change in activation energies of NR/CR blends under mechanical aging condition. The decrease of activation energy by dynamic loading of NR/CR blends $\left(\Delta U_{d}\right)$ is remarkably higher (18-19 times) than that of the neat NR, which indicates that the incompatibility of rubbers affects mainly materials resistance to dynamic loading. In the complex aging, the small difference (less than $5 \%)$ between $\left(\Delta U_{c}\right)$ and the sum $\Delta U_{t}+\Delta U_{d}$ indicates that heat and dynamic loading factors act independently. This may allow evaluating the complex aging process through separate results of heat aging and mechanical aging regimes of NR/CR blends.

\section{Data Availability}

The hardness (shore A), tensile strength, elongation at break, permanent compression, and rebound property data, as well as the calculated activation energy data, used to support the findings of this study are included within the article.

\section{Conflicts of Interest}

The authors declare that they have no conflicts of interest.

\section{Acknowledgments}

This research was funded by the National Subject KC 02.06/ 16-20. Moreover, the authors would like to thank Polymer Center, HUST, for the overall support.

\section{References}

[1] R. D. Buttle and R. D. Brown, Natural Aging of RubberChange in Physical Properties over 40 Years, Rapra Technology Ltd., Shawbury, USA, 2000.

[2] M. E. Abu-Zeid, Y. A. Youssef, and F. A. Abdugrasqul, "Accelerated aging of natural rubber," Journal of Applied Polymer Science, vol. 32, no. 1, pp. 3345-3348, 1986. 
[3] D. J. Harmon and H. L. Jacobs, "Degradation of natural rubber during mill mastication," Journal of Applied Polymer Science, vol. 10, no. 2, pp. 253-257, 1996.

[4] S. Z. Salleh, M. Z. Ahmad, and H. Ismail, "Properties of natural rubber/recycled chloroprene rubber blend: effects of blend ratio and matrix," Procedia Chemistry, vol. 19, pp. 346-350, 2016.

[5] H. Ismail and H. C. Leong, "Curing characteristics and mechanical properties of natural rubber/chloroprene rubber and epoxidized natural rubber/chloroprene rubber blends," Polymer Testing, vol. 20, no. 5, pp. 509-516, 2001.

[6] T. Q. Nguyen, V. Dang, T. Tran, H. Nam, and C. Bui, "Calculation of vulcanization parameters of natural rubber and blend NR/CR with various fillers," Vietnam Journal Chemical, vol. 56, no. 3, pp. 290-295, 2018.

[7] Z. Hrnjak-Murgić and J. Jelenčić, "Change of network structure of natural rubber vulcanizate with thermal aging," Macromolecular Materials and Engineering, vol. 283, no. 1, pp. 21-25, 2000.

[8] R. N. Datta, "A review on heat and reversion resistance compounding," Progress in Rubber, Plastics and Recycling Technology, vol. 19, no. 3, pp. 143-170, 2003.

[9] S.-S. Choi, "Influence of rubber composition on change of crosslink density of rubber vulcanizates with EV cure system by thermal aging," Journal of Applied Polymer Science, vol. 75, no. 11, pp. 1378-1384, 2000.

[10] H.-T. Chiu and P.-A. Tsai, "Aging and mechanical properties of NR/BR blends," Journal of Materials Engineering and Performance, vol. 15, no. 1, pp. 88-94, 2006.

[11] B. Moon, J. Lee, S. Park, and C. S. Seok, "Study on the aging behavior of natural rubber/butadiene rubber (NR/BR) blends using a parallel spring model," Polymers, vol. 10, no. 6, 2018.

[12] R. Fan, Y. Zhang, C. Huang, Y. Zhang, Y. Fan, and K. Sun, "Effect of crosslink structures on dynamic mechanical properties of natural rubber vulcanizates under different aging conditions," Journal of Applied Polymer Science, vol. 81, no. 3, pp. 710-718, 2001.

[13] V. Pimolsiriphol, P. Saeoui, and C. Sirisinha, "Relationship Among thermal ageing degradation, dynamic properties, cure systems, and antioxidants in natural rubber vulcanisates," Polymer-Plastics Technology and Engineering, vol. 46, no. 2, pp. 113-121, 2007.

[14] E. F. Ngolemasango, M. Bennett, and J. Clarke, "Kinetics of the effect of ageing on tensile properties of a natural rubber compound," Journal of Applied Polymer Science, vol. 102, no. 4 , pp. $3732-3740,2006$

[15] M. H. Al-Maamori and S. H. Al-nesrawy, "Aging effect on hardness of SBR/NR/BR, SBR/NR composites by using industrial scraps as a filler," Australian Journal of Basic and Applied Sciences, vol. 8, pp. 579-584, 2014.

[16] A. M. Bishai and F. F. Hanna, "Effect of natural ageing on the dielectric properties of natural rubber-channel black mixtures," British Polymer Journal, vol. 8, no. 3, pp. 83-86, 1976.

[17] A. R. Azura, S. Ghazali, and M. Mariatti, "Effects of the filler loading and aging time on the mechanical and electrical conductivity properties of carbon black filled natural rubber," Journal of Applied Polymer Science, vol. 110, no. 2, pp. 747752, 2008.

[18] P. Zhang, X. Shi, J. Li, G. Yu, and S. Zhao, "Effects of hot-air aging and dynamic fatigue on the structure and dynamic viscoelastic properties of unfilled natural rubber vulcanizates," Journal of Applied Polymer Science, vol. 107, no. 3, pp. 1911-1916, 2008.
[19] L. Munoz, L. Vanel, O. Sanseau et al., "Fatigue crack growth dynamics in filled natural rubber," Plastics, Rubber and Composites, vol. 41, no. 7, pp. 273-276, 2012.

[20] S. M. Clarke, F. Elias, and E. M. Terentjev, "Ageing of natural rubber under stress," The European Physical Journal E, vol. 2, no. 4, pp. 335-341, 2000.

[21] H. Gu and Y. Itoh, "Aging behaviors of natural rubber in isolation bearings," Advanced Materials Research, vol. 163-167, pp. 3343-3347, 2011.

[22] J.-H. Choi, H. Jin Kang, H.-Y. Jeong, T.-S. Lee, and S.-J. Yoon, "Heat aging effects on the material property and the fatigue life of vulcanized natural rubber, and fatigue life prediction equations," Journal of Mechanical Science and Technology, vol. 19, no. 6, pp. 1229-1242, 2005.

[23] P. Zhang, X. Shi, J. Li, G. Yu, and S. Zhao, "The structure change of dynamically fatigued unfilled natural rubber vulcanizates," Journal of Applied Polymer Science, vol. 115, no. 6, pp. 3535-3541, 2010.

[24] W. V. Mars and A. Fatemi, "Factors that affect the fatigue life of rubber: a literature survey," Rubber Chemistry and Technology, vol. 77, no. 3, pp. 391-412, 2004.

[25] P. Ghosh, R. Mukhopadhyay, and R. Stocek, "Durability prediction of NR/BR and NR/SBR blend tread compounds using tear fatigue analyser," Kgk-Kautschuk Gummi Kunststoffe, vol. 69, no. 6, pp. 53-55, 2016.

[26] G. S. R. P. Brown and M. J. Forrest, Long-Term and Accelerated Ageing Tests on Rubbers, Smithers Rapra Technology, Shrewsbury, USA, 2000.

[27] R. Brown, T. Butler, and S. W. Hawley, Aging of RubberAccelerated Heat Ageing Test Results, Rapra Technology Ltd., Shawbury, USA, 2001.

[28] H. C. C. C. S. Woo, W. D. Kim, S. H. Park, and S. H. Lee, "Constitutive models for rubber VI," in Fatigue Life Prediction of Aged Natural Rubber Materials, G. Heinrich, M. Kaliske, A. Lion, and S. Reese, Eds., CRC Press, Taylor \& Francis Group, Boca Raton, FL, USA, pp. 15-18, 2009.

[29] F. E. Ngolemasango, M. Bennett, and J. Clarke, "Degradation and life prediction of a natural rubber engine mount compound," Journal of Applied Polymer Science, vol. 110, no. 1, pp. 348-355, 2008.

[30] Y. Itoh and H. S. Gu, "Prediction of aging characteristics in natural rubber bearings used in bridges," Journal of Bridge Engineering, vol. 14, no. 2, pp. 122-128, 2009.

[31] C. S. Woo and W. D. Kim, "Fatigue life prediction of heataging vulcanized natural rubber," Key Engineering Materials, vol. 32, no. 323, pp. 518-521, 2006.

[32] L. H. Sperling, Introduction to Physical Polymer Science, John Wiley \& Sons, Hoboken, NJ, USA, 4th edition, 2005.

[33] J. E. Mark, Physical Properties of Polymers Handbook, Springer, New York, NY, USA, 2007.

[34] В. Е. Гуль and В. Н. Кулезнев, “Структура и мечанические свойства Шолимеров,” Высшая школа, Москва,стр, vol. 3, no. 3-4, pp. 322-325, 1979. 